\title{
Covid-19: Implementation e-voting Blockchain Concept
}

\author{
Mustofa Kamil ${ }^{\mathrm{a}, 1}$, Po Abas Sunarya ${ }^{\mathrm{b}, 2}$, Untung Rahardja ${ }^{\mathrm{b}, 3^{*}}$, Nuke Puji Lestari Santoso ${ }^{\mathrm{b}, 4}$, Muhammad \\ Iqbal ${ }^{\mathrm{b}, 5}$ \\ ${ }^{a}$ Universitas Pendidikan Indonesia, Jl. Dr. Setiabudi No.229, Isola, Kec. Sukasari, Kota Bandung, Jawa Barat, Indonesia \\ ${ }^{b}$ Universitas Raharja, Jl. Jenderal Sudirman No.40, RT.002 / RW.006, Cikokol, Kota Tangerang, Indonesia \\ ${ }^{1}$ Mustofa.kamilun@upi.edu; ${ }^{2}$ abas@raharja.info; ${ }^{3}$ untung@raharja.info $*{ }^{*}$ nuke@ raharja.info; ${ }^{5}$ iqbal@raharja.info \\ * corresponding author
}

ARTICLE INFO ABSTRACT

Article history:

Received 27-05-2020

Revised 19-06-2020

Accepted 26-12-2020

Keywords:

Covid-19,

E-voting,

Blockchain,

cryptography

\begin{abstract}
The current situation of the Covid-19 pandemic is currently increasing public concern about the community. The government has especially recommended Stay at Home and the implementation of PSBB in various regions. One of the concerns is when the election of regional leaders to the general chairman. Even though there is already a safeguard regulation, this is not considered safe in the current Covid19 pandemic. The solution in this research is the use of a blockchainbased E-voting system to help tackle election unrest during Covid-19. Where e-voting with blockchain technology can be carried out anywhere through the device without the need to be present in the voting booth, reducing data fraud, accurate and decentralized voting results that can be accessed by the public in real-time. The use of cryptographic protocols is applied for data transfer between system components as well as valid system security. This research method uses SUS trial analysis in a significant system of the Covid-19 pandemic situation. The implication that the SUS Score analysis shows 90 shows an acceptable E-voting system, meaning that the community can accept it because it brings positive and significant impacts such as effectiveness and efficiency.
\end{abstract}

Copyright (C) 2017 International Journal of Artificial Intelligence Research.

All rights reserved.

\section{INTRODUCTION}

Technology has now entered the 4.0 era; all activities in all fields should be supported by the digitalization of transformation [1], [2]. However, in the case of voting activities in Indonesia that we still feel at this time are still using conventional methods, namely voting on paper. Fraud that often occurs in elections is no longer denied by the manipulation of ballot data sent to the center because it is done directly at the polling stations (polling stations), where the funding of this election project can add to the burden of the state in 5 years [3][4]. Then the outbreak of Covid-19 is the government's consideration for the election. Covid-19, which has now looted to various worlds, begins with the spread of China [5]. Graphic Fig1 is a case of Covid-19 globally when the beginning of the pandemic continues to increase from China, Europe, and others [6]. Common signs of infection will be Covid-19 infection with an average incubation period of 5-6 days to 14 days, namely in acute breathing with, for example, shortness of breath, fever, and cough [7] . 


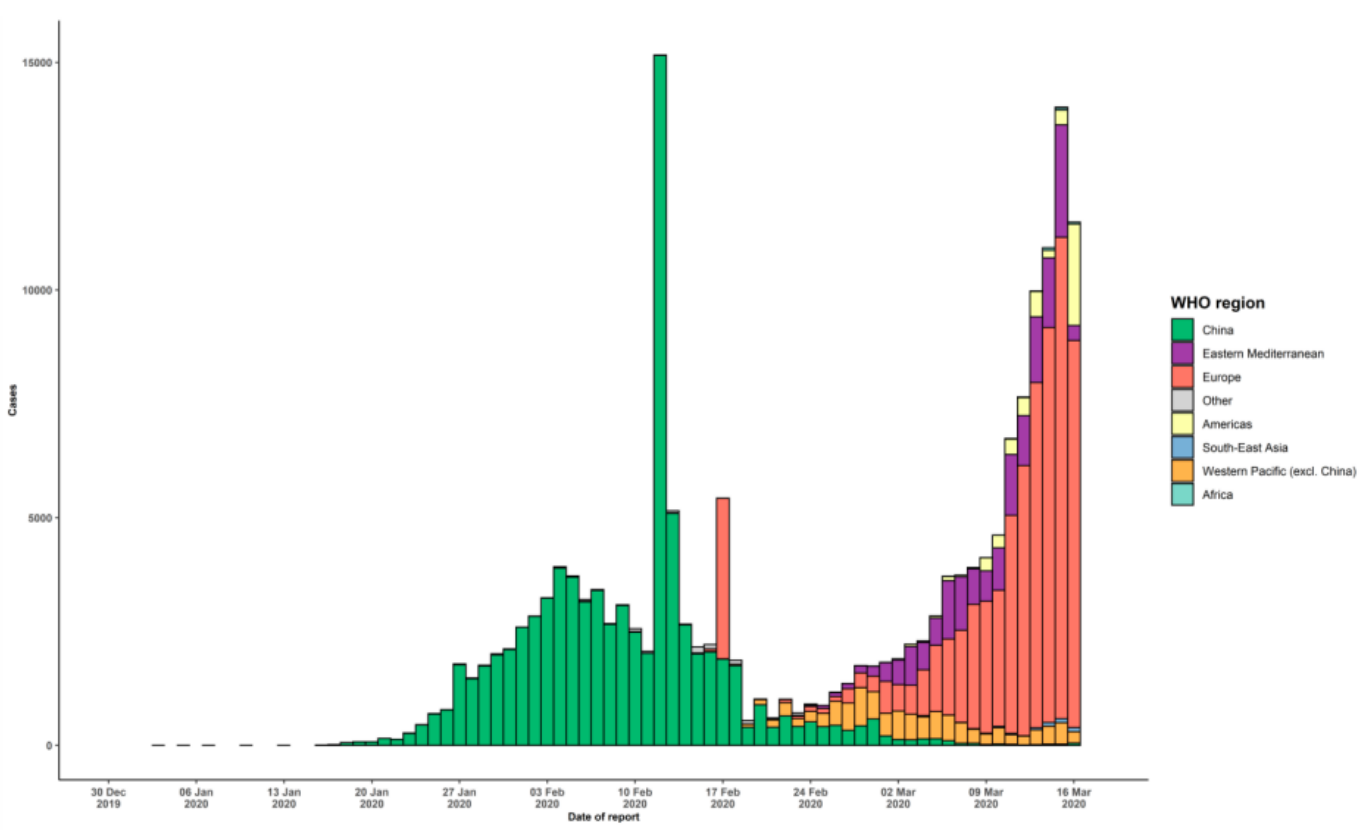

Figure 1. Epidemic curve of confirmed COVID-19, by date of report and WHO region through (17 March 2020)

The biggest impact of Covid-19 influences distance learning in order to maintain social distancing[8]. So, when the general chair (election) or regional elections (pilkada) that occur in Indonesia indeed become a question of how it can go according to the Covid-19 protocol in order to maintain social distancing. As a result of the COVID-19 pandemic, the KPU has issued a KPU decision letter Number: 179 / PL.02-kpt / 01 / KPU / III / 2020 explaining the rules for delaying several stages of the 2020 elections, including the inauguration and the working period of the Voting Committee (PPS), verification of the support requirements of individual candidates, the establishment of the Voter Data Update Officer (PPDP) and the implementation of matching and research (coklit), as well as updating and compiling the voter list [9]. The importance of the government's role in announcing the restriction order during this pandemic is to prevent the spread of the Covid-19 virus [10]. This will be discussed in this study that E-voting with blockchain technology can assist in the electoral process in the situation of the Covid-19 pandemic with the blockchain e-voting framework [11]. This e-voting is a modern voting activity. Therefore, the system and application that will be created will answer some voting needs with the implementation of blockchain technology [12] [13]. The blockchain technology application can answer with the nature of the blockchain, which is transparency, meaning that the data stored is open to the public, thereby increasing fairness and truth. Anonymity, only the voter himself knows information about votes, and all ballots collected have nothing to do with voters. Dependability means that every vote will be counted and cannot be replaced, duplicated or deleted, and produces credible results. Eligibility is only a verified user and has voting rights who can vote and vote. Verifiability is a system that is open to checking the system procedures' truth to the results issued [14] .

\section{Literature Review}

This research also collected ten literature reviews to strengthen perspective from E-voting and blockchain. Satria Damai Kurnia Hu,et al. conducted this research discussing electronic voting or voting using the media of an application and by using blockchain technology, because conventional voting itself is still hampered by its security aspects, as well as more expensive cost issues, and also the implementation of an E-voting only in terms of security is still in doubt, therefore in this E-voting, blockchain technology is included. Where this blockchain we cannot modify, delete data so, the authenticity of the data is guaranteed [15]. Research on blockchain applied in the education sector has also succeeded in making students more active and motivated in blockchain-based iLearning learning [16]. Research conducted by Sandi Rahmadika et al., who discussed blockchain technology is a technology to maintain data security at a low cost that has been decentralized to maintain data confidentiality without the involvement of third parties [17]. 
Furthermore, 2017 research that discusses, blockchain technology is an up-and-coming technology behind bitcoin and is very interesting to face a challenge that arises in managing authorization that utilizes the consistency of blockchain technology, to manage access control on behalf of restricted devices [18]. Then research on an election guard application was made to be a real count media by using blockchain technology so that data can be distributed well without worrying about hacking attacks [19]. Another study by Snehal Kadam, Khushaboo Chavan, et al. explained the application of the blockchain as a service to implement a distributed electronic voting system with an E-voting application to increase security and reduce the costs of holding elections [20]. Next research Rasim Alguliyev et al about exploring the E-voting system as one of the main tools of e-democracy and analyzing its strengths and weaknesses for effective decision making [21]. Other blockchain research on the application of blockchain technology in higher education assessment systems so that the information delivered is transparent and decentralized [22]. Kashif Mehboob Khan conducted the study, Junaid Arshad and Muhammad Mubashir Khan, entitled "Secure Digital Voting System Based on Blockchain Technology." This study discusses the e-voting system using blockchain technology to improve system resilience and utilize the benefits of blockchain to achieve an effective scheme on e-voting systems [23]. The latest research is the application of E-voting with SMS (Short Message Service) technology to get speed, security, and accuracy of data that is designed simply so that the costs incurred are relatively inexpensive [24].

\section{A. Blockchain}

Blockchain is a data structure that is arranged as a block and connected with other blocks to form a chain; each new block is processed by nodes that enter the P2P (Peer-to-Peer) Blockchain network. To determine the mechanism of the Blockchain, we must have a basic concept of the block. The block consists of block headers, and the main block includes raw serial transactions. This hash value transaction is a raw transaction containing the unique identifier (TxID). Then the identity value of all transactions for each block forms the Merkel tree leaf node [25]. Each breastfeeding must follow the PoW (Proof-of-Work) consensus mechanism [26]. There are several types of Blockchain, namely 1) Blockchain is private, meaning that permission is only specified by one entity, where there is only one domain that is trusted. 2) Blockchain without permission for examples such as Ethereum or bitcoin means that anyone can "write" and can participate, and 3) Blockchain permission to identify nodes that can update data and control simultaneously and can control who can issue transactions [27]. Adopting blockchain technology in distributing databases on an E-voting system can reduce sources of fraud and database manipulation with methods based on rotating nodes in making Blockchain [28].

\section{METODE}

\section{A. System Usability Scale (SUS)}

This study uses the System Usability Scale (SUS) test. SUS is a subjective assessment of the system made in terms of usability, such as effectiveness, efficiency, and satisfaction felt by the community towards the E-voting system with blockchain. To calculate SUS scores, it takes a variety of data variables. The following four steps were carried out by researchers. SUS scores can be generated through several stages in which researchers conduct data collection. The population from various disdukcapil in the electoral district is in progress. Thus, the number of folks who have voting rights to choose the regional head can be seen.

$$
n=\frac{N}{1+N e^{2}}
$$

The next stage of the total population who have voting rights is recalculated using the Slovin formula to determine the right number of samples. Next is the stage of distributing the questionnaire given to all sample respondents through online media such as Google forms; each answer from the respondent has a value on a Likert scale. 


$$
X=\frac{(((R 1)+(R 2)+(R 3)+(R 4)+(R 5)+(R 6)+(R 7)+(R 8)+(R 9)+(R 10)+}{(R 11)+(R 12)+(R 13)+(R 14)+(R 15))) * 2,5) * N}
$$

The final step of all variables of each statement that the respondent gave when following the questionnaire will be accumulated by putting it in the variables R1 through R15 and calculated to produce the total value of the SUS score.

\section{B. Blockchain E-Voting Framework}

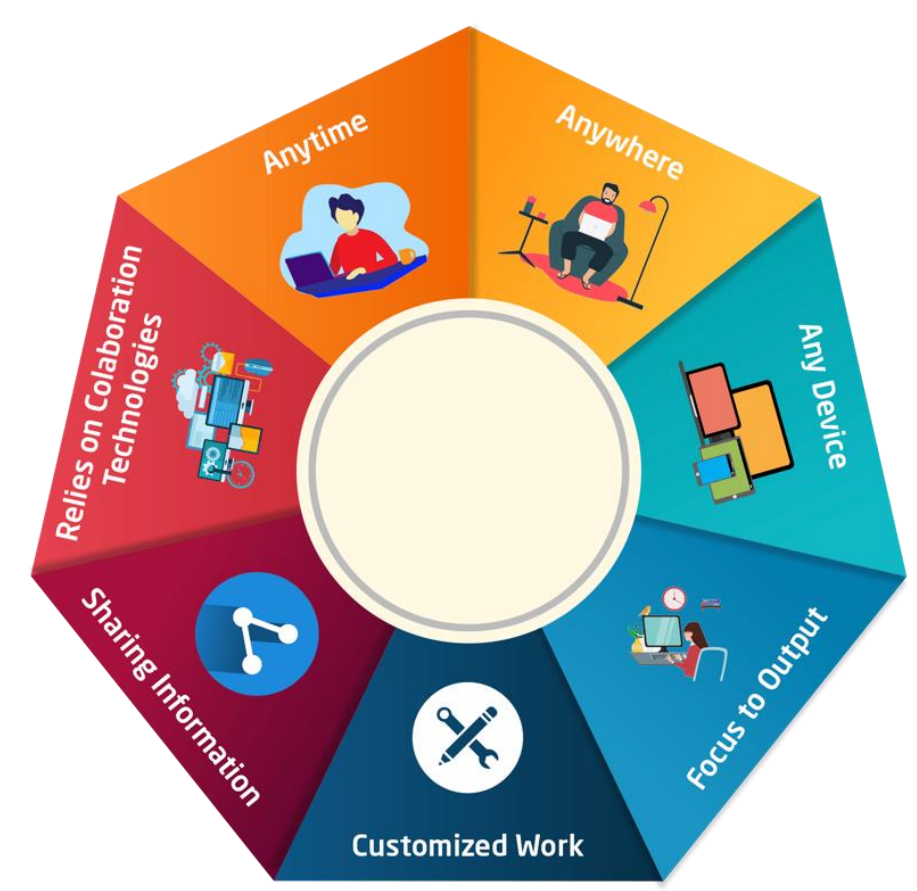

Fig 2. Blockchain E-Voting Framework

The blockchain-based E-voting system has implemented a new framework by the current condition of the Covid-19 pandemic, where the previously commonly carried out framework was transformed into a new thing that must be done when the Covid-19 Pandemic, a more flexible, effective and efficient framework very needed. The new framework concept combines 7 (seven) elements that have been transformed along with the Covid-19 pandemic period.

a. Anytime, meaning that we can do work with any weight at this time, and difficulty is not limited by time. If previously, the voting process was obliged to follow the government's schedule, so now every individual has full control over the time held to use their voting rights, of course, with a predetermined deadline.

b. Anywhere, work can be anywhere, and anytime is the most critical thing in the Covid-19 pandemic. The e-voting system that is designed can be accessed online with an internet connection, so there is no need to vote based on the specified place. The public can use any device to provide voting rights such as smartphones, tablets, personal computers, and notebooks, which are elements that combine current sophisticated technology with traditional voting to prevent the spread of Covid19.

c. Focus to Output; If the voting is traditionally focused on input provided by the community, then with this system, the organizer only needs to focus on the output produced. The system automatically handles all input processes, voice security, and user privacy can be protected with the blockchain. Furthermore, the traditional voting process has generally been predetermined, wants to proceed as planned, is very inflexible to disturbances such as the Covid-19 pandemic.

d. Customized Work, to solve these problems, Blockchain-based E-voting systems can customize the voting flow so that it is safe for the committee and the public.

e. Sharing Information, the output provided by the Blockchain E-voting System is shared 
transparently. However, while maintaining the privacy of the voting rights owner.

f. Relies on Collaboration Technologies, the transformation of dependent habits from ballots using paper and manual calculations to become entirely dependent on technology.

\section{RESULT AND DISCUSSION}

\section{A. Application Design}

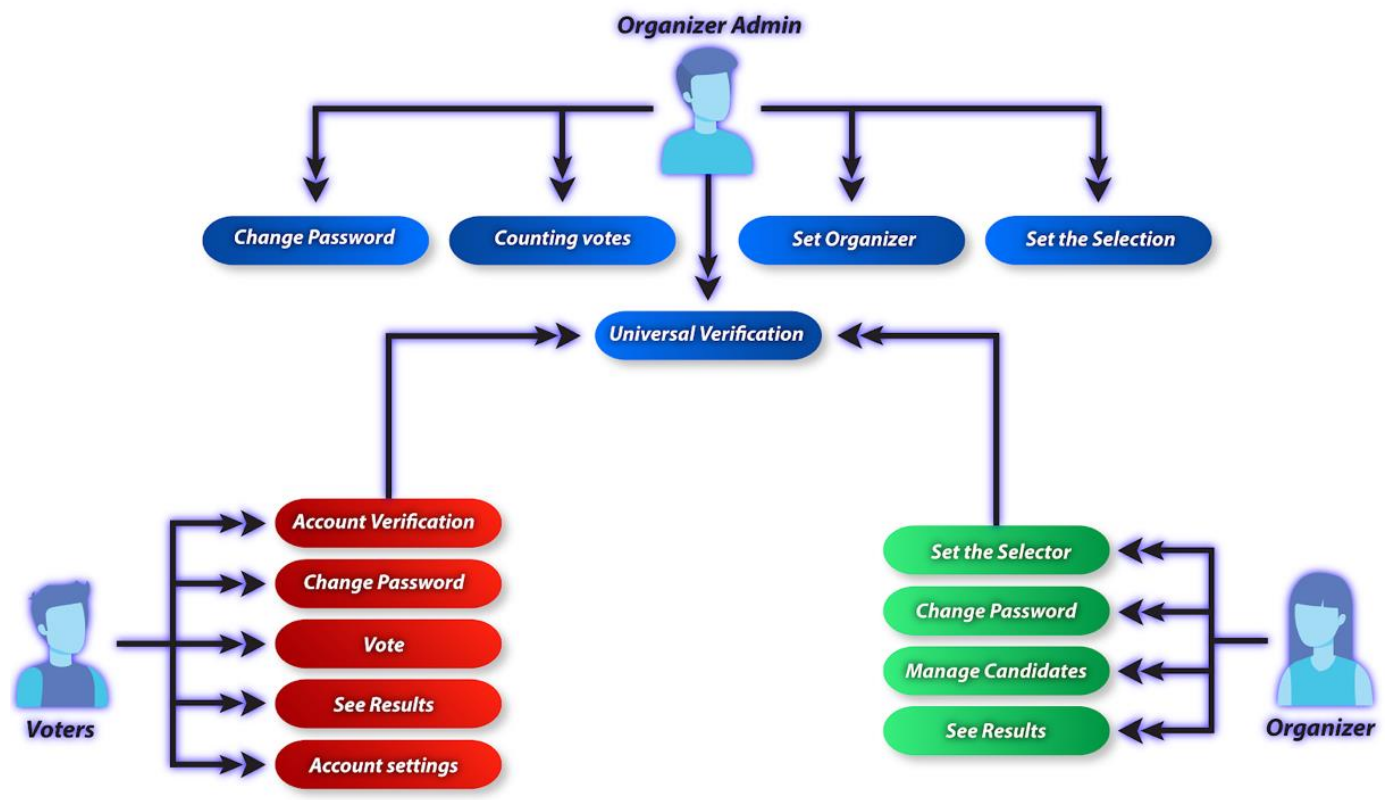

Fig 3. Use Case Diagram

In Fig3, use case diagram E-voting blockchain flow from each actor. The interface design of the website application is adjusted to the existing access rights, namely the Organizer Admin, Organizer, and Voters. Each application design aimed at each access right has different according to function and needs. The application design for the organizer admin has functions to manage to vote, manage organizer data, and manage data access rights from those who run the voting. The interface design for the organizer admin consists of a change password page, view results, manage elections, manage organizers, and manage access right. The organizer's application design has functions for managing voter data and managing candidate data that follows the voting.

The interface design for the organizer consists of a change password page, view results, manage voters, and manage candidates. While the design of applications for voters has the function to vote, see and check the votes that have been done. The voter interface design consists of the change password, view result, vote, and individual ballot verification pages. Besides, some pages can be accessed by all users, including the login page, register, account setup, and universal ballot verification. The login, register, and account setup pages have functions to help users manage their accounts when they first access the application. The universal ballot verification page has a function to check the sound that has entered the system. 


\section{B. System Architecture}

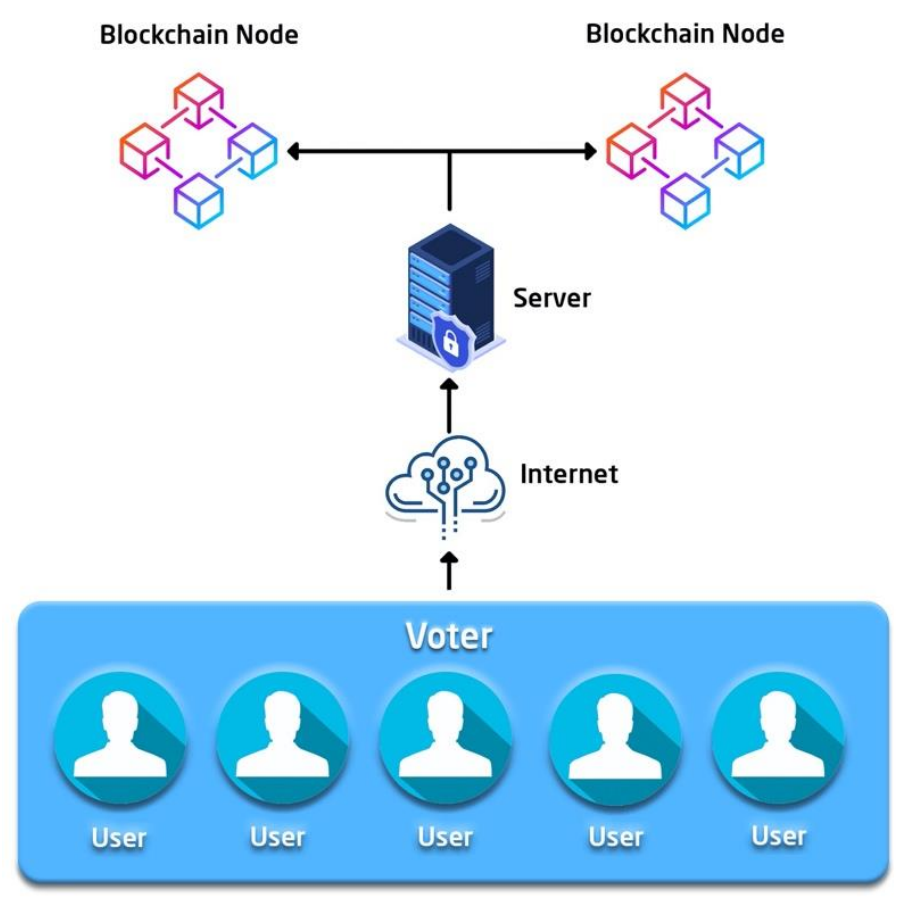

Fig 4. System Architecture

Fig4 explains the architecture system design on blockchain-based E-voting. This architecture system has components in the form of Blockchain Node, Web Server, and Client Computer. The client computer component is a computer that is used at an election place to be used in voting. The client computer accesses web pages on the webserver. All data and web application interactions between client computers and web servers use HTTP or HTTP methods. The web server component is a web application that provides voters and organizers services in the voting process. Web Server uses a computer (centralized) to manage all activities carried out from the client computer (voter).

Web Server is also connected to a local database to store data needed in voting, such as election data, user data (voter, candidate, organizer), and other supporting data. The webserver is also connected to a blockchain node to make API calls. The blockchain component of the node provides an API call with the JSON RPC method. This component is a computer in a peer-to-peer network of blockchain. The JSON RPC API call is used by the webserver to manage the blockchain in meeting voting needs. Ballot generated by the voter (client computer) will be saved to the blockchain on the blockchain node by the webserver. With blockchain technology accompanied by Multi Chain tools can sort out the results of valid and invalid votes. A valid ballot is a ballot that has; 1) Signature (digital, sender's address) of an organizer, voters who vote, and the node where the ballot was sent as proof of the validity of the ballot. 2) The recipient's address as the polling place for the ballot is addressed. 3) An asset as a voting right or means of voters to vote and send ballots. 4) Data in the form of candidates chosen by voters with a particular format signifies a valid election (voting). 5) Valid status (on the blockchain) as a ballot sign is valid and has been accepted in the voting system.

\section{System Evaluation}

To find community satisfaction with the blockchain-based E-voting system, researchers used the System Usability Scale (SUS) because evaluating SUS shows how the benefits, effectiveness, and efficiency of the blockchain-based E-Voting system through questionnaires distributed to each respondent who has voting rights - starting from getting the data of a known population of 5,521 people who entered the permanent voter list. Moreover, to facilitate the evaluation process, the Slovin formula is used to find the right number of samples. Population information is then entered into the $\mathrm{N}$ variable; then, it will be calculated with a $1 \%$ error margin to produce the following. 


$$
\begin{gathered}
n=\frac{5521}{1+5521 .(0,1)^{2}} \\
n=\frac{5521}{56,21} \\
n=98,22 \rightarrow 98
\end{gathered}
$$

Obtained a sample size of 98.22 , if rounded up to 98 respondents. Questionnaires, in the form of google forms, are distributed through links and e-mails. Each respondent has the right to state each question asked. The Likert scale is used to calculate the weighted values of statements given on a scale of 1 to 5 . The values of the Likert scale will be accumulated to produce an individual SUS score. The researcher uses the average value of the statement the respondent gave. Then from the average value of the respondents' statements entered into variables R1 through R10.

$$
\begin{gathered}
X=((4)+(5)+(5)+(3)+(3)+(2)+(3)+(5)+(3)+(3)) * 2,5 \\
X=\frac{90 * 98}{98} \\
X=\frac{8.820}{98}=90
\end{gathered}
$$

Starting with finding the value of X, which is the total value of the overall SUS score of the statements following the questionnaire with a valid status, the number who took the questionnaire was 98 respondents. From the statement of 98 respondents, the average value is obtained and entered into the variables R1 to $\mathrm{R} 10$, then multiplied and divided by the number of $\mathrm{N}$, namely the number of respondents. It was resulting in a SUS score of 90.

\section{E-VOTING BLOCKCHAIN SUS}

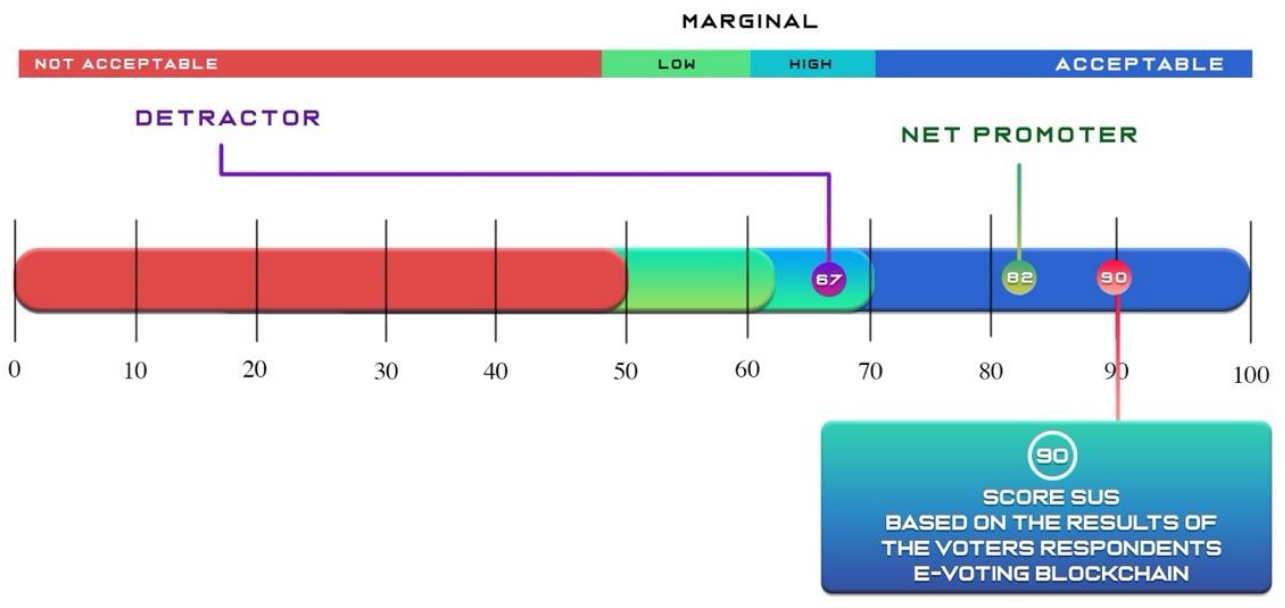

Fig 5. System Usability Scale (SUS) graph

With the SUS Score reaching 90, the Blockchain E-voting system is proven to be able to answer the community's need to stay in the general election without having to worry about gathering somewhere to 
lead to the Covid-19 pandemic. The E-voting system's positive impact makes it a strength that can meet the level of user satisfaction.

Table 1. SUS Score from Acceptability of Level

\begin{tabular}{cc}
\hline Acceptability & Range \\
\hline Acceptable & $70-100$ \\
Marginal-High & $62-70$ \\
Marginal-Low & $50-62$ \\
Not Acceptable & $0-50$ \\
\hline
\end{tabular}

In addition to evaluating using SUS, this study also evaluates by calculating the reliability of the E-voting blockchain system, based on the normal variant of items produced by the following respondents:

Table 2. Total Variant Item E-Voting Blockchain System

Variant Item $2.4551 .2891 .8860 .9892 .397 \quad 0.9992 .276 \quad 3.109 \quad 1.361 \quad 2.668$

From the Variant items above, the researcher will calculate the total reliability, to get the Cronbach's alpha results as follows:

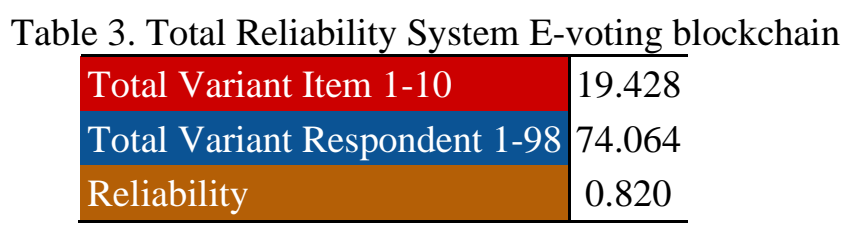

Based on table 1, the SUS score with a range of 70-100 is declared to be in the Acceptable category; of course, the E-voting blockchain system that gets a SUS score of 90 already meets the requirements as a system with an Acceptable category. In SUS, another type of category can determine whether a system in the future will be used by many people referred to as Net Promoter; if a system gets a SUS score > 82, then it can be declared as a Net Promoter. Conversely, if you get $<67$, then it is declared as a detractor, which means that in the future, the system will experience a decrease in users because it is less useful for people's lives. Blockchain E-voting system already qualifies as a Net Promoter because the resulting score exceeds> 82 ie 90 besides the Blockchain E-voting system gets a reliability score of $0.820>0.6$ can be interpreted that the system is believed to be able to be the right solution by respondents. From the evaluation results above obtained values that indicate that the system is suitable for meeting the needs of the community, the SUS score reached 90, and reliability was 0.820 . Illustrates that with the presence of an E-voting block system, regional, regional and general chairpersons who are active, safe, and efficient during the Covid-19 pandemic. Viewed from the side of the drawbacks with e-voting that is using the internet network, where in addition to using the internet e-voting blockchain, it will not run smoothly other than that in the blockchain public network to process every vote transaction that takes 10 to 20 seconds.

\section{CONCLUSIONS}

The Covid-19 pandemic situation has delayed the holding of elections and the extension of office in the present. Increasingly sophisticated technology must participate in these problems. So this study discusses the use of blockchain-based E-voting for digitizing voting. The hope with this E-voting system is to reduce the meeting of human physical contact in election activities without having to be present in the voting booth. The use of blockchain technology with a strong cryptographic protocol makes a secure encryption block so that the results of votes made by the public are real, safe, and transparent without being able to be manipulated. Using ballot, which has a function as proof validity of a vote that has been chosen by the voter/community against the candidates. Then the multi-chain function is useful in order to facilitate storing large amounts of E-voting data. New information and previous information are stored to produce new blocks. The system will continue to monitor the incoming blocks and continue to renew the chain when new blocks arrive, so there is no duplication of data or collisions between incoming data. 
Stored data is transparent and can be accessed by the public, with guaranteed privacy for the voting rights owner. SUS Score Analysis results show the number 90.5. This indicates that the blockchain E-voting system provides satisfaction for the public to vote in terms of security when the covid-19 pandemic, the efficiency of time and place of voting, and can be declared effective. It can prevent the spread of the Covid19 pandemic at a low cost by high system security and accuracy of the collected voice information because no one can manipulate it. Viewed from the side of the drawbacks with e-voting that is using the internet network, where in addition to using the internet e-voting blockchain, it will not run smoothly other than that in the blockchain public network to process every vote transaction that takes 10 to 20 seconds. Suggestions for future research to further develop and refine the program with the E-voting application in the form of mobile apps with phone number authentication connected by blockchain technology.

\section{ACKNOWLEDGMENT}

The researcher would like to thank the Pekerti Grant for funding this research to run successfully. Thank Raharja of University and the Islamic University of Sheikh Yusuf Tangerang for collaborating on completing this paper by the projected research writing. Moreover, to the Alphabet Incubator, who helped in input and also a contribution to this research.

\section{REFERENCES}

[1] Q. Aini, S. Riza Bob, N. P. L. Santoso, A. Faturahman, and U. Rahardja, "Digitalization of Smart Student Assessment Quality in Era 4.0," International Journal of Advanced Trends in Computer Science and Engineering, vol. 9, no. 1.2, pp. 257-265, Apr. 2020, doi: 10.30534/ijatcse/2020/3891.22020.

[2] Sudaryono, N. Lutfiani, Suseno, and Q. Aini, "Empirical Study of Research Performance Leading to Education 4.0 using the iLearning Method," International Journal of Advanced Trends in Computer Science and Engineering, vol. 8, no. 1.5, pp. 264-268, Nov. 2019, doi: 10.30534/ijatcse/2019/4681.52019.

[3] M. M. Abdalla, D. Darjat, and A. A. Zahra, "RFID (RADIO FREQUENCY IDENTIFICATION) SEBAGAI TEKNOLOGI PENDUKUNG PEMILU DIGITAL LEGISLATIF," Transient: Jurnal Ilmiah Teknik Elektro; TRANSIENT, VOL. 4, NO. 3, SEPTEMBER 2015DO - 10.14710/transient.4.3.794-801 , Nov. 2015, [Online]. Available: https://ejournal3.undip.ac.id/index.php/transient/article/view/10040.

[4] A. M. Fauzi, "Perilaku Pemilih Menjelang Pemilu 2019," Journal of Islamic Civilization, vol. 1, no. 1 SEArticles, pp. 40-48, Apr. 2019, doi: 10.33086/jic.v1i1.918.

[5] H. Wang et al., "Phase-adjusted estimation of the number of coronavirus disease 2019 cases in Wuhan, China," Cell discovery, vol. 6, no. 1, pp. 1-8, 2020.

[6] "WHO Coronavirus Disease (COVID-19) Dashboard." https://covid19.who.int/ (accessed May 23, 2020).

[7] R. Tosepu, J. Gunawan, D. S. Effendy, H. Lestari, H. Bahar, and P. Asfian, "Correlation between weather and Covid-19 pandemic in Jakarta, Indonesia," Science of The Total Environment, p. 138436, 2020.

[8] A. R. Setiawan, "Scientific Literacy Worksheets for Distance Learning in the Topic of Coronavirus 2019 (COVID-19)," 2020.

[9] Pusat Penelitian Politik - Lembaga Ilmu Pengetahuan Indonesia (P2P-LIPI), "Dampak Pandemi COVID-19 Terhadap Pilkada 2020 - Politik Lipi.” http://www.politik.lipi.go.id/kolom/kolom-2/politik-nasional/1398-dampakpandemi-covid-19-terhadap-pilkada-2020 (accessed May 20, 2020).

[10] S. Engle, J. Stromme, and A. Zhou, "Staying at Home: Mobility Effects of COVID-19," SSRN Electronic Journal, 2020, doi: 10.2139/ssrn.3565703.

[11] U. Rahardja, S. Sudaryono, N. P. L. Santoso, A. Faturahman, and Q. Aini, "Covid-19: Digital Signature Impact on Higher Education Motivation Performance," International Journal of Artificial Intelligence Research, vol. 4, no. 1, May 2020, doi: 10.29099/ijair.v4i1.171.

[12] U. Rahardja, A. N. Hidayanto, T. Hariguna, and Q. Aini, "Design Framework on Tertiary Education System in Indonesia Using Blockchain Technology," 2019 7th International Conference on Cyber and IT Service Management, CITSM 2019, pp. 5-8, 2019, doi: 10.1109/CITSM47753.2019.8965380. 
[13] T. Hidayat and R. Mahardiko, "A Systematic Literature Review Method On AES Algorithm for Data Sharing Encryption On Cloud Computing," International Journal of Artificial Intelligence Research, vol. 4, no. 1, 2020.

[14] N. Purwati, "Perancangan sistem e-voting untuk pemilihan kepala daerah (pilkada)," Bianglala Informatika, vol. 3 , no. $1,2015$.

[15] S. D. K. Hu, H. N. Palit, and A. Handojo, "Implementasi Blockchain: Studi Kasus e-Voting," Jurnal Infra, vol. 7, no. 1, pp. 183-189, 2019.

[16] Q. Aini, U. Rahardja, and A. Khoirunisa, "Blockchain Technology into Gamification on Education," IJCCS (Indonesian Journal of Computing and Cybernetics Systems), vol. 14, no. 2, pp. 1-10, 2020, doi: 10.22146/ijccs.53221.

[17] S. Rahmadika, D. R. Ramdania, and M. Harika, "Security analysis on the decentralized energy trading system using blockchain technology," Jurnal Online Informatika, vol. 3, no. 1, pp. 44-47, 2018.

[18] A. Ouaddah, A. A. Elkalam, and A. A. Ouahman, "Towards a novel privacy-preserving access control model based on blockchain technology in IoT," in Europe and MENA Cooperation Advances in Information and Communication Technologies, Springer, 2017, pp. 523-533.

[19] P. KPU and D. W. I. F. H. S. WIBOWO, "PERANCANGAN DAN IMPLEMENTASI TEKNOLOGI BLOCKCHAIN PADA SISTEM PENCATATAN HASIL REKAPITULASI PEMILU BERDASARKAN FORMULIR C1."

[20] S. Kadam, K. Chavan, I. Kulkarni, and A. Patil, "Survey on Digital E-Voting System by using Blockchain Technology," International Journal of Advance Scientific Research and Engineering Trends, 2019.

[21] F. Yusifov, R. Alguliyev, and R. Aliguliyev, "Multi-criteria Evaluation+ Positional Ranking Approach for Candidate Selection in E-voting," Decision Making: Applications in Management and Engineering, vol. 2, no. 2, pp. 65-80, 2019.

[22] Q. Aini, N. Lutfiani, F. Hanafi, and U. Rahardja, “Application of Blockchain Technology for iLearning Student Assessment," IJCCS (Indonesian Journal of Computing and Cybernetics Systems), vol. 14, no. 2, 2020, doi: $10.22146 /$ ijccs.53109.

[23] K. M. Khan, J. Arshad, and M. M. Khan, "Secure digital voting system based on blockchain technology," International Journal of Electronic Government Research (IJEGR), vol. 14, no. 1, pp. 53-62, 2018.

[24] S. Risnanto, "Aplikasi Pemungutan Suara Elektronik/E-Voting Menggunakan Teknologi Short Message Service dan At Command,” Jurnal Teknik Informatika, vol. 10, no. 1, 2017.

[25] Y. Wu, “An e-voting system based on blockchain and ring signature," Master. University of Birmingham, 2017.

[26] Y. Liu and Q. Wang, “An E-voting Protocol Based on Blockchain.," IACR Cryptology ePrint Archive, vol. 2017, p. 1043, 2017.

[27] C. Cachin and M. Vukolić, "Blockchain consensus protocols in the wild," arXiv preprint arXiv:1707.01873, 2017.

[28] R. Hanifatunnisa and B. Rahardjo, "Blockchain based e-voting recording system design," in 2017 11th International Conference on Telecommunication Systems Services and Applications (TSSA), 2017, pp. 1-6. 